\title{
Encephalopathy due to visceral larva migrans
}

\author{
DAVID SUMNER and ELLIS G. F. TINSLEY \\ From the Departments of Neurology and Pathology, \\ St. James's Hospital, Leeds
}

For some time a syndrome of massive eosinophilia associated with respiratory and other symptoms has been recognized. The condition carries on the whole a good prognosis, is self-limiting and is most commonly seen in children, often occurring in several members of the same family. Frequently observed in the tropics or the subtropics, it has been variously described as Loeffler's syndrome, tropical eosinophilia, familial eosinophilia, or benign eosinophilic leukaemia. In 1940 this syndrome was shown to be associated with multiple eosinophilic granulomata in the liver, and in 1950, Mercer and his colleagues (Mercer, Lund, Bloomfield, and Caldwell, 1950) found that with this eosinophilia, Nematode larvae were sometimes to be seen in the tissues. In 1952, Beaver, Snyder, Carrera, Dent, and Lafferty suggested that the syndrome resulted from infection in man by a Nematode normally parasitic upon a lower animal; under these conditions the normal Nematode life cycle does not take place but is blocked by an eosinophilic granulomatous reaction at the stage where the larvae are in the tissues. At this point systemic symptoms and signs may appear, in addition to an eosinophilia, and it was for this stage that they coined the term 'visceral larva migrans'.

The condition has been reported most frequently from the more southern states of the U.S.A. and in addition to the eosinophilia, the clinical features include malaise, pyrexia, bronchitis, 'pneumonitis', enlargement of the liver (and less commonly the spleen), lymphadenopathy, skin rashes, and subcutaneous granulomata. In view of the wide distribution of the larvae in the viscera, it would be surprising if the brain were to escape and indeed, Dent, Nichols, Beaver, Carrera, and Staggers in 1956, describing the necropsy findings in a child who suffered from this condition but had died from another illness, found five larvae per gram of wet brain tissue. Despite this, clinical involvement of the nervous system has rarely been reported. Reviewing 58 cases Lewis, Yadav, and Kern (1962) found mention of convulsions in but three patients, one in Britain (Dickson and Woodcock, 1959) and two in America (Milburn and Ernst, 1953), while Moore (1962) described a further example which presented with convulsions and encephalitis.

For an adult to be affected is equally rare and Lorentz (1962), who made the diagnosis in a West Indian immigrant in London, could find but three examples in the literature, and none in an Englishborn individual. In 1964, Brain and Allan described the case of a young Englishwoman who had visceral larva migrans presenting essentially the picture of varying focal epilepsy. Although the larva was not found it seemed likely that the infecting parasite was a Toxocara and it is of interest that five years before the onset of her illness she had gone to live in Calcutta.

The present example is reported not only because of the paucity of accounts of clinical involvement of the nervous system but also because of the apparent rarity of the condition in the adult.

CASE REPORT

The patient was a 57-year-old school mistress, teaching sixth form mathematics. She had never visited the tropics and has lived all her life in the north of England. She had never kept any pets and denied any but the most casual contact with cats or dogs, but she was a pathological hoarder and as a result of this had lived for some years in considerable squalor. The hoarding had been going on for many years and she collected not only new and unwanted objects (as, for example, four unused paraffin heaters, a 20 -ft. extending ladder, and 87 pound jars of Bovril), but all rubbish and uneaten food. Nothing had been placed in a dustbin for 10 years but the full extent of the hoarding only came to light when she was admitted to hospital and her house could be visited. Figure 1, which shows some of the 3,600 full milk bottles which were stored in the bedrooms and Figure 2, which shows her kitchen, give some idea of what the house was like. Although it is not our contention that her recent encephalopathy was directly related to this longstanding psychological abnormality (in the sense of sharing the same pathology), it seems reasonable to conclude that the state of her house may well have provided a route for Nematode infection. For many years she had lived apart from her husband, but he 


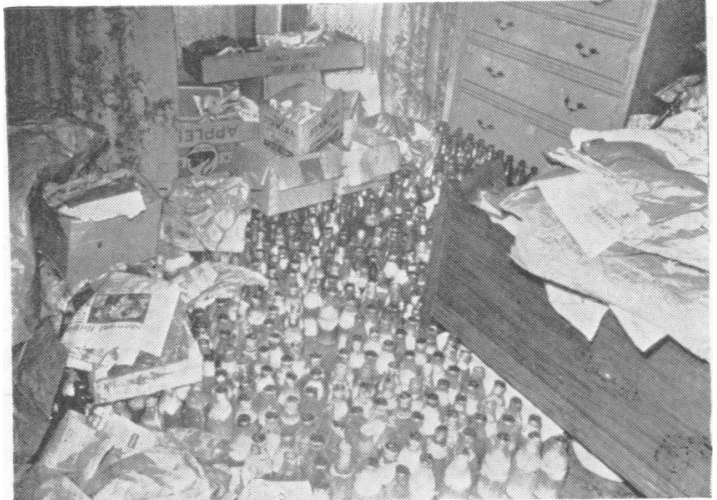

FIG. 1. The patient's bedroom.

nevertheless visited her about twice a week and was thus able to say that in September 1965, she began to look ill and at the beginning of October, she stopped work and retired to bed, where she lay confused and incontinent. The day before her admission to hospital (25 October) she was found to have a temperature of $103^{\circ} \mathrm{F}$. but within 24 hours she became apyrexial and remained so. She herself could give no clear account of her condition and

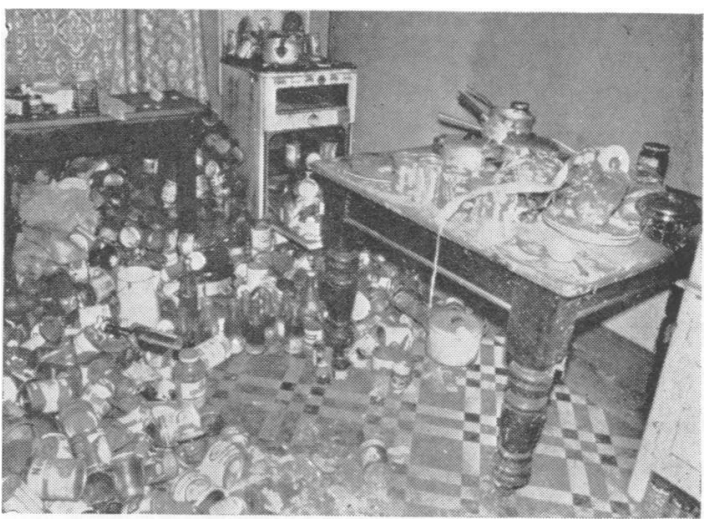

FIG. 2. The patient's kitchen.

although she knew the day and the date, she had no recollection of the events of the preceding week. She had no knowledge of current affairs and was totally unable to carry out the serial seven test. On the other hand, she knew that the area of a circle was $\pi r^{2}$. On general examination the only abnormality was in the chest, where there was diminished air entry at the right lung base and in this area scattered expiratory rhonchi could be heard.

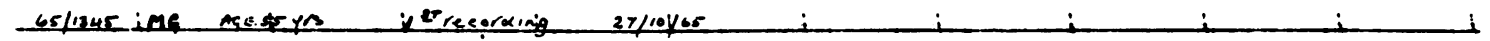

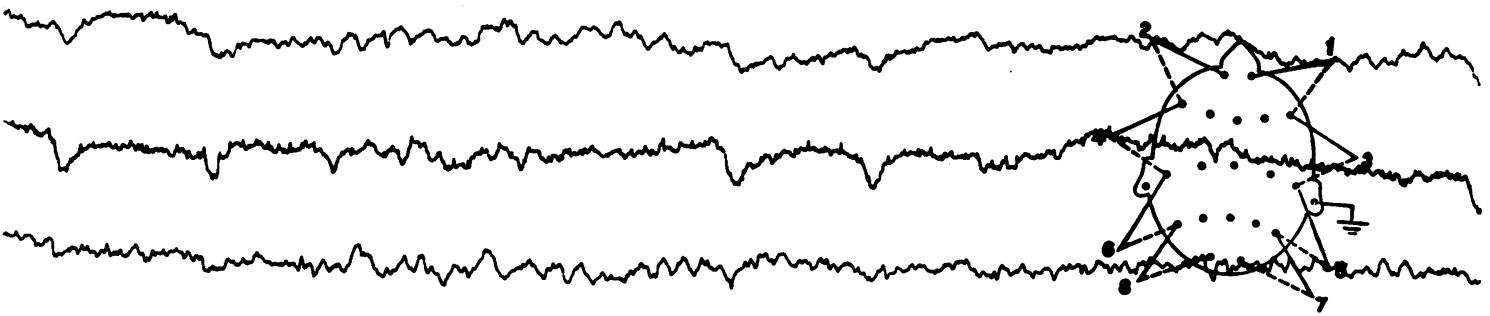

Temporal montage

(5)

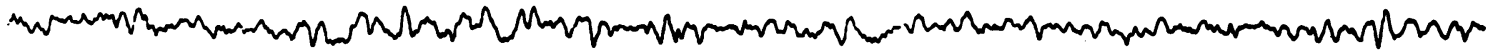

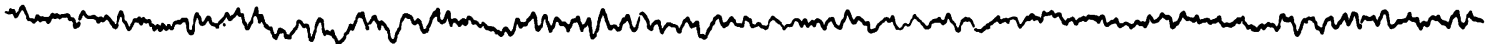

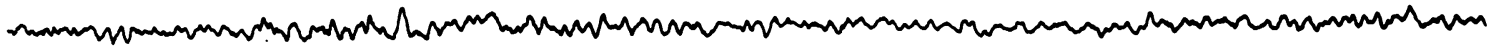

FIG. 3. The E.E.G. recorded on admission showing an increase in slow wave activity in anterior leads, particularly on overbreathing. 


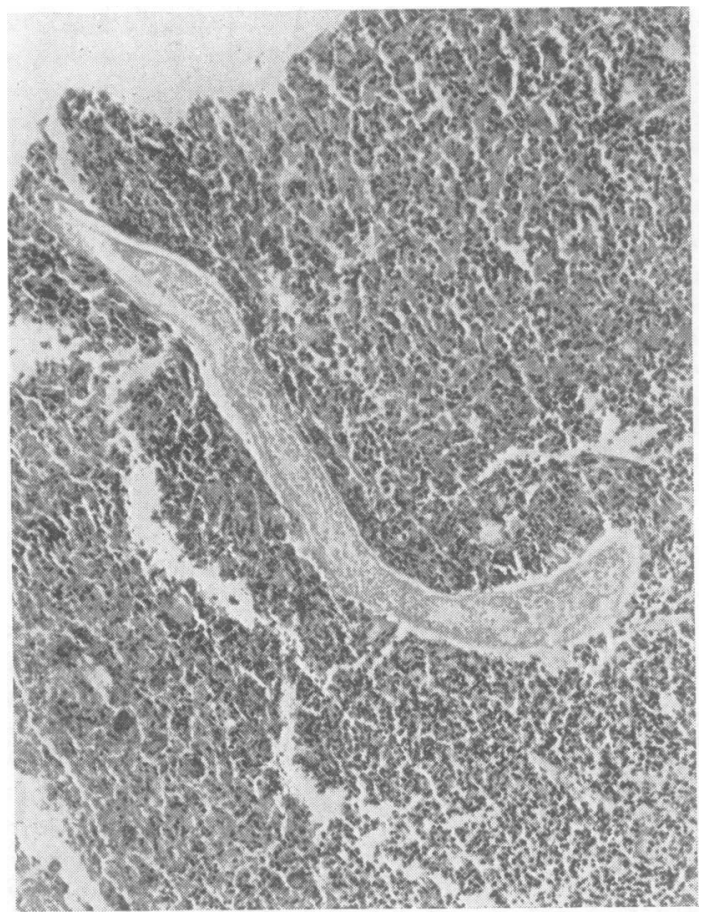

FIG. 4. Liver biopsy showing the granuloma and Nematode larva.
Neither the liver nor the spleen was palpable. In the central nervous system the only abnormality (apart of course from confusion) was the presence of bilateral extensor plantar responses.

The cerebrospinal fluid was normal, but the E.E.G. showed some diffuse abnormality, particularly on overbreathing (Fig. 3).

The striking finding on investigation was a considerable eosinophilia of $47 \%$ of a total W.B.C. count of 9,800 per c.mm., the eosinophilia persisting throughout her stay in hospital, and a search for helminth parasites was commenced. Faeces were examined on many occasions by concentration methods but no ova, larvae, or adult worms were discovered. Twice the stomach was washed out in the early morning and the aspirate similarly searched with negative results. However, an $x$-ray examination of the chest showed a high right diaphragm, which suggested that there might be some enlargement of the liver, although this could never be felt. Liver function tests at this time were abnormal, suggesting considerable liver damage: serum bilirubin $0.5 \mathrm{mg} . / 100$ ml.; serum alkaline phosphatase 28 K.A. units; thymol flocculation weakly positive; thymol turbidity and zinc sulphate turbidity at the upper limit of normal; S.G.P.T. 127 units; S.G.O.T. 62 units; total serum proteins $6.2 \mathrm{~g} / 100 \mathrm{ml}$.; (albumin 3.3, globulin 2.9); electrophoretic pattern normal.

Three weeks after admission to hospital a needle biopsy of the liver was performed. A small white nodule was seen in the middle of the specimen, and microscopically it consisted of an inflammatory granuloma some $3 \mathrm{~mm}$. in diameter (Fig. 4). Necrotic liver cells and
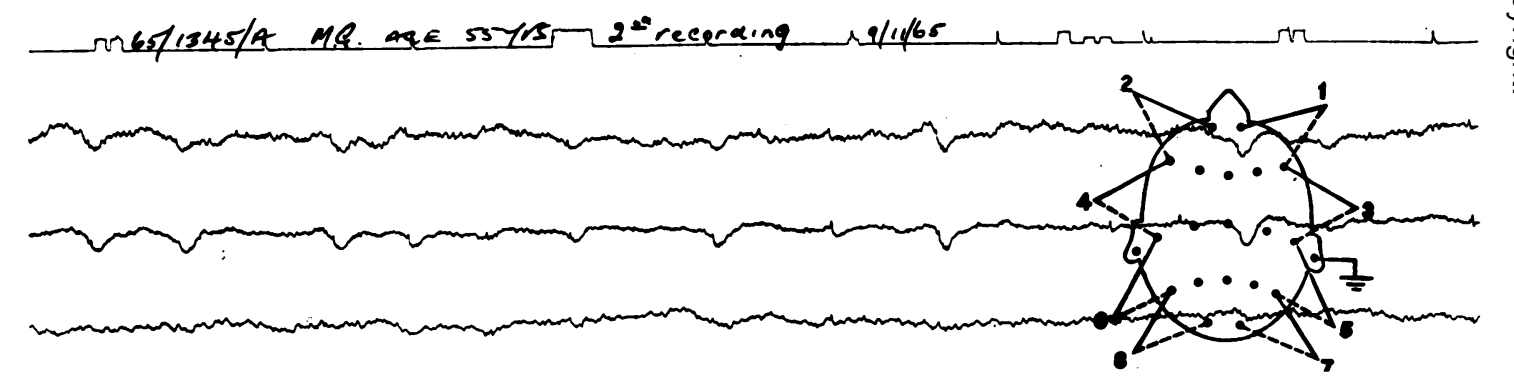

Temporal montage
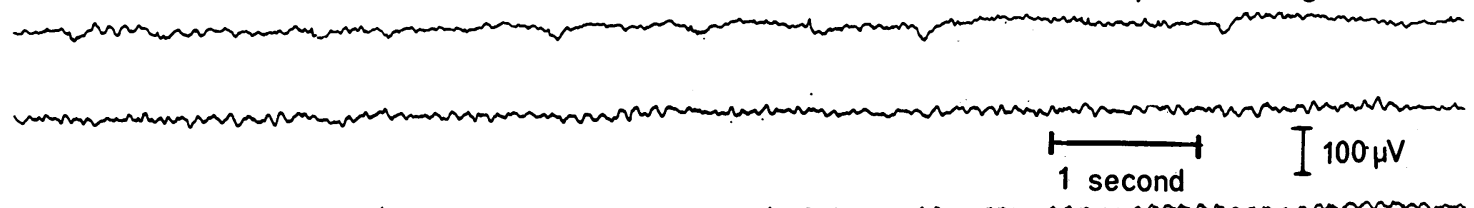

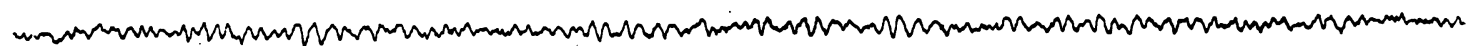

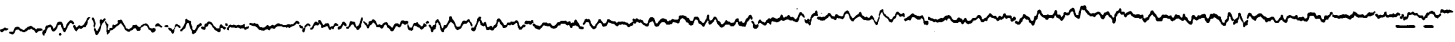

FIG. 5. The E.E.G. recorded three weeks after admission showing considerable resolution in the changes seen earlier. 
breaking down polymorphs and eosinophils made up the centre, together with numerous Charcot-Leyden crystals. Embedded in the necrotic mass was a Nematode larva. Surrounding the centre was a narrow band of eosinophil leucocytes and outside this a broader area of young fibrous tissue, heavily infiltrated with eosinophils and other chronic inflammatory cells. The rest of the liver biopsy showed normal liver tissue.

The greatest length of larva seen in any one section measured about $620 \mu$ and the maximum diameter measured $54 \mu$. Apart from nuclear debris and a chitinous coat, no identifiable structures were noted in the larva. It appeared to be in process of dissolution.

Later the deltoid muscle was biopsied. Part of the specimen was digested and examined for larvae and the rest was cut up into several blocks and many sections were taken. No evidence of any inflammation or of any larvae was seen.

Following success with the liver biopsy, specimens of serum were sent for serological tests for filariasis, hydatid disease, and ascariasis. All were negative. Skin tests using specific Nematode antigens were also performed. Trichinella gave a positive reaction, Ascaris gave a doubtful positive, while Toxocara and Hydatid antigens were negative.

Over the course of the next few weeks the patient's confusion cleared spontaneously and the plantar responses became flexor. This change was reflected in the E.E.G. recorded three weeks after her admission to hospital (Fig. 5).

She was discharged from hospital two months after admission, having continued to make a steady and spontaneous recovery both clinically and biochemically. Her convalescence was complicated by an episode of depression which responded well to drugs, and six months after the onset of her illness she was back at work teaching A level mathematics with complete confidence and success.

By mid-January 1966 the white blood cell count was 6,000 per c.mm. with only $1 \%$ eosinophils. Stools were examined periodically for a further eight months but no ova, larvae, or adult worms were seen.

\section{DISCUSSION}

Despite the non-specific pattern of neurological disease and the apparent rarity of central nervous system involvement in visceral larva migrans, there can be little doubt that this is the correct diagnosis. The combination of a self-limiting disease with transitory signs in the chest, transitory pyrexia, and a massive eosinophilia, to say nothing of the presence of an eosinophilic granuloma containing larval remnants in the liver, can point in no other direction. No alternative explanation is forthcoming to account for the encephalopathy and indeed it would be extremely unlikely for this and the systemic illness to be unrelated. In view of the very few recorded examples of central nervous system in- volvement in visceral larva migrans, any attempt to delineate a clinical pattern is obviously impossible. It is of interest, however, that the few previous examples in the literature presented with epilepsy or 'convulsions'. In this connexion, the important work of Woodruff, Bisseru, and Bowe (1966) must be mentioned. They found positive skin tests to Toxocara in $7.5 \%$ of a population of epileptics as against an incidence of $2.1 \%$ in normals and postulated that the epilepsy was due to the presence of granulomata in the brain. If this is indeed so, then it seems quite possible that with the passage of time our patient may herself develop epilepsy.

More than 150 cases of visceral larva migrans have been reported in the literature. In the great majority of cases where the infecting Nematode has been identified, Toxocara canis was the cause (Beaver et al., 1952) although other Nematodes have been shown to cause a similar clinical syndrome. Some cases of visceral larva migrans have been diagnosed on clinical grounds in association with altered serum protein levels, haematological and serological evidence. In many cases liver biopsy, either at laparotomy or by needle aspiration, has substantiated the diagnosis by showing the typical eosinophilic infiltration and granulomata in the liver tissue. Larvae have been seen in only a few of these cases and anatomical identification of the larva has been undertaken on probably less than 40 occasions (Beaver et al., 1952). The second stage larva of Toxocara canis, the form of larva causing visceral larva migrans, measures up to $400 \mu \times 20 \mu$ (Nichols, 1956). In only one previous case (Beaver and Danaraj, 1958) has a larva similar in size to that described in this paper been noted as causing visceral larva migrans. Here typical granulomata were found in the liver, but the larvae (fourth stage larvae of Ascaris lumbricoides) were seen in the bronchioles only, in association with characteristic inflammatory changes. The larva from our patient cannot be identified anatomically as it has undergone internal autolysis and only a part of its length is available for measurement.

Normally the larval forms of Toxocara canis can remain viable for periods up to a year in the tissues of its natural host the dog, while a similar long life is possible in unnatural hosts, as has been shown experimentally in mice, guinea-pigs, monkeys, and man. This is, no doubt, the cause of the persistent eosinophilia which occurs in human infection. In this case the eosinophilia lasted a few weeks only and histologically the larva appears to have been dead at the time of biopsy. It would seem probable, therefore, that our patient is permanently cured of this infection. 
On the other hand clinical and experimental evidence suggests that an initial systemic infection by larval Nematodes not normally associated with that host results in little systemic illness but that re-infection results in severe systemic illness of an allergic type (Kerr, 1938). The two forms of the infection are also associated with rather different patterns of local reaction of the tissues to the larvae. Only on re-infection are the typical eosinophilic and epithelioid cell granulomata produced. Our case shows these features both clinically and histologically. In at least one described case re-infection resulted in an ill-defined encephalopathy. It would seem more common for nervous system involvement to be due either to the presence of typical granulomata causing epilepsy (Dickson and Woodcock, 1959; Woodruff et al., 1966; Moore, 1962; Snyder, 1961; Dent and Carrera, 1953) or to associated encephalitis probably viral in origin (Woodruff et al., 1966; Mochizuki, Tomimura, and Oka, 1954). The latter seems to have some peculiar association with Nematode infections. Our patient recovered spontaneously from the encephalopathy and never showed the cerebrospinal fluid changes associated with encephalitis, suggesting that the reaction was a form of allergy.

\section{CONCLUSION}

An adult woman presented with an encephalopathic syndrome due to visceral larva migrans. The diagnosis was substantiated by needle biopsy of the liver, which showed a typical granuloma of epithelioid cells and eosinophil leucocytes surrounding a central area of necrosis containing a dead Nematode larva larger than any previously described in this site. The larva remains unidentified. It is suggested that this may not be the first occasion on which this patient has been infected with such a Nematode. As no evidence of continuing infection remains despite the fact that she was given no treatment, it is concluded that man is an unnatural host for this parasite.

Our thanks are due to Dr. Leahy, of the Department of Psychiatry, who referred this patient in the first instance; to Dr. Exley, of the Department of Electro-encephalography, who was responsible for the E.E.G. recordings and interpretation; to Dr. Losowski, of the Department of Medicine, who carried out the liver biopsy with such striking success; and to Mr. Howard, of the Department of Medical Photography, for his invaluable assistance.

\section{REFERENCES}

Beaver, P. C., and Danaraj, T. J. (1958). Pulmonary ascariasis resembling eosinophilic lung; autopsy report with description of larvae in the bronchioles. Amer. J. trop. Med. Hyg., 7, 100-111.

-, Snyder, C. H., Carrera, G. M., Dent, J. H., and Lafferty, J. W. (1952). Chronic eosinophilia due to visceral larva migrans; report of three cases. Pediatrics, 9, 7-19.

Brain, R., and Allan, B. (1964). Encephalitis due to infection with Toxocara canis. Lancet, 1, 1355-57.

Dent, J. H., and Carrera, G. M. (1953). Eosinophilia in childhood caused by visceral larva migrans. J. La med. Soc., 105, 275-280.

—, Nichols, R. L., Beaver, P. C., Carrera, G. M., and Staggers, R. J. (1956). Visceral larva migrans, with a case report. Amer. $J$. Path., 32, 777-803.

Dickson, W., and Woodcock, R. C. (1959). Visceral larva migrans. Arch. Dis. Childh., 34, 63-67.

Kerr, K. B. (1938). The cellular response in acquired resistance in guinea pigs to an infection with pig ascaris. Amer. J. Hyg., 27, 28-51.

Lewis, P. L., Yadav, V. G., and Kern, J. A. (1962). Visceral larva migrans (Larval granulomatosis). Report of a case and review of the literature. Clin. Pediat., 1, 19-26.

Lorentz, I. T. (1962). Visceral larva migrans. Report of a case. J. trop. Med. Hyg., 65, 112-116.

Mercer, R. D., Lund, H. Z., Bloomfield, R. A., and Caldwell, F. E. (1950). Larval ascariasis as a cause of eosinophilia with visceral manifestations. Amer. J. Dis. Child., 80, 46-58.

Milburn, C. L., Jr., and Ernst, K. F. (1953). Eosinophilia-hepatomegaly syndrome of infants and children; report of a case due to invasion of liver by nematode larvae. Pediatrics, 11, 358-367.

Mochizuki, H., Tomimura, T., and Oka, T. (1954). Cerebrospinal nematodiasis as a provoking factor in Japanese B enceohalitis: an experimental approach. J. infect. Dis., 95, 260-266.

Moore, M. T. (1962). Human toxocara encephalitis with lead encephalopathy. J. Neuropath. exp. Neurol., 21, 201-218.

Nichols, R. L. (1956). The etiology of visceral larva migrans: I. Diagnostic morphology of infective second-stage toxocara larvae. J. Parasit., 42, 349-362.

Snyder, C. H. (1961). Visceral larva migrans. Ten years' experience. Pediatrics, 28, 85-91.

Woodruff, A. W., Bisseru, B., and Bowe, J. C. (1966). Infection with animal helminths as a factor in causing poliomyelitis and epilepsy. Brit. med. J., 1, 1576-79. 